\title{
Development of the academic contribution to humanitarian logistics and supply chain management
}

\section{Editorial overview Management Research News, Volume 32, Issue 11}

\author{
Peter H. Tatham \\ Centre for Human Systems, Cranfield University, DCMT Shrivenham, Swindon, UK
}

\section{Karen M. Spens}

Department of Marketing, Hanken School of Economics, Supply Chain Management and Corporate Geography, Helsinki, Finland, and

\section{David Taylor \\ Logistics and Operations Management Section, Cardiff Business School, Cardiff, UK}

Effective delivery of humanitarian aid is an issue that is becoming increasingly important as part of the overall response to disasters, not least as there is strong evidence that both natural and man-made disasters around the world are increasing in terms of their magnitude, frequency and impact (UN, 2006). For example, annual disasters in 2000-2004 were 55 per cent higher than between 1995 and 1999. The number of people affected by natural disasters has also increased, 33 per cent more between 2000 and 2004 compared to the 1995 to 1999 period (CRED, 2008). By the same token, the developing scenario of world food shortages that has started to appear in 2007-2008 is creating increasing demand for humanitarian relief and the United Nations Food and Agriculture Organisation (FAO) has estimated that 100million extra people will require food aid in 2008 alone. Furthermore, as world stocks of major food commodities such as wheat, rice and soya continue to diminish, greater pressure will be put on aid supply chains as future emergencies arise. The scale of such increases underlines the importance of the increased attention that is being given to emergency relief response operations (IFRC, 2005; Fritz Institute, 2005; Balcik and Beamon, 2008).

As the demand for assistance increases, it is important that not only is more aid made available, but that the logistics systems and supply chains for delivering the required commodities from source-of-origin to recipients are both effective and efficient.

Unfortunately, there is clear evidence that many humanitarian supply chains are less efficient than they could be, for example the UN Office for the Coordination of Humanitarian Affairs stated in 2006 that "Over the past few years, the international response to humanitarian emergencies has demonstrated that the present system does not always meet the basic needs of affected populations in a timely and effective manner" (OCHA, 2006).

It is also clear that organising efficient and effective humanitarian supply chains is no easy task. The environment into which aid is delivered is almost always challenging in the extreme for a wide variety of reasons including social and political upheaval or military conflict. At the same time there are often, potentially, very significant operational difficulties in managing logistics and supply chain activity ranging from degradation or destruction of information and communications systems, difficulties in coordinating physical supply lines and associated damage to the physical infrastructure (roads, bridges, etc.), to a lack of logistics management expertise. In practice many aspects of the environment into which aid must be delivered are frequently beyond the control of 
the logistics professional and must, therefore, be taken as a given - at least in the short run. Nevertheless, improving the operational performance of aid supply chains is an area that can be and, indeed, must be addressed by aid organisations in their continuing quest to both improve the service to the beneficiaries and to provide increasing confidence to donors by demonstrating efficient use of resources. This focus is particularly true given that, according to some sources, as much as 80 per cent of the activity of a non-governmental organisation (NGO) is logistic related (Wilton Park, 2005; Van Wassenhove, 2006).

Fortunately, an increasing number of humanitarian aid agencies have become aware of the need for improved performance of logistics and supply chain management, not least through the efforts of organisations such as the Fritz Institute and the United Nations Joint Logistics Centre (UNLJC). At the same time there has been a growing appreciation in the academic community of the need for, and potential of, research and education in the area of humanitarian logistics and supply chain management. As a result, a number of initiatives have been instigated at universities in different parts of the world; one such is the development of "HUMLOG (2009)", a group of universities and aid organisations that came together in 2006 in order "to develop coordinated research in the area of humanitarian logistics in disaster preparedness, response and recovery with the intention of influencing future activities in a way that will provide measurable benefits to persons requiring assistance" (www.humloggroup.org). The HUMLOG group includes Hanken School of Economics and Business Administration in Helsinki (Finland), Jönköping International Business School from Sweden, the Kwame Nkrumah University of Science \& Technology (KNUST) in Ghana, the University of Manitoba in Canada, the Norwegian School of Management in Oslo, the National Defence University of Finland, the Norwegian Defence Command and Staff College, and UNJLC. In the UK, Cardiff and Cranfield Universities, which are also members of HUMLOG, established the "Cardiff/Cranfield Humanitarian Logistics Initiative" (CCHLI) in an endeavour to make the most effective contribution to improving humanitarian supply chain activity.

The publication of this special edition of MRN is an early output of the HUMLOG and CCHLI initiatives. In October 2007, CCHLI organized the first of what will be a bi-annual International Symposium on humanitarian logistics and supply chain management. The aim of the conference was to provide a forum to bring together academics and practitioners from around the world to discuss current and potential future areas for academic research in humanitarian supply chain management. Over 40 people attended the conference with delegates coming from Europe, Asia, Africa and North America. Twenty-two papers were presented covering a wide variety of topics ranging from operational issues to strategic and policy matters. Most of the papers reported preliminary investigations into humanitarian logistics activity, and almost all pointed to the need for more thorough and detailed research.

In reviewing both the papers presented at the symposium and other published literature, it is apparent that the field of humanitarian logistics and supply chain management is still in its infancy both from an academic point of view as well as in its practice. Currently, this sector could be said to be at a "pre-supply chain management" stage and this is, arguably, akin to the situation previously faced by other sectors of the economy - for example food retailing in the 1980s or the automotive industry in the early 1990s. Interestingly, in each of these sectors the development of improved supply chain management was triggered by a change in the operation of their market. Thus, in automotives it was the increasing market share gained by Toyota and other Japanese 
manufacturers as a result of their lean policies, whilst in food retailing the move to centralised and contracted-out distribution (first adopted by companies such as Sainsbury in the UK, Walmart in the US and Carrefour in France) led, as a necessary competitive response, to dramatic improvements in supply chains across the sector. In these and other areas, the increased focus on logistics and supply chain management has been driven by commercial competitive pressures and has resulted in its eventual elevation to become a key part of company operations and strategy.

In the humanitarian sector such competitive pressures are absent or at least much less direct - although, perversely, the results of failure are much more significant as they can be counted in terms of unnecessary deaths rather than reduced profits. The question that must be asked, therefore, is what will trigger the development of a more concerted, professional and effective approach to supply chain management in this sector On the one hand, it may be that increasing demand for aid combined with increased fuel and resource costs that will put an even greater focus on the need for efficient supply chains. Alternatively it is possible that by focusing on improved supply chain management, one or two major aid agencies will be able to demonstrate the benefits to both service levels and costs, and that other agencies will then achieve similar improvements - not least through donor pressure to emulate the "market leaders".

The academic community has a clear role to play in such developments by providing objective evidence of the need for improved supply chain management, by developing methodologies and concepts demonstrating how supply chain performance can be improved, by helping to transfer knowledge and best practice in supply chain management from the commercial sector, and by provision of education and training programmes to increase the professional standards for humanitarian logistics practitioners. A further, and potentially crucial, role for the academic community could be to highlight the importance of improved supply chain management to the most senior management and decision makers in humanitarian organisations and within the donor community.

However, the development of any academic field of study is necessarily a tentative and iterative process, and it takes time for a coherent body of knowledge and literature to develop. The papers included in this Special Edition were selected through a double blind refereeing process from those presented at the $2007 \mathrm{CCHLI}$ International Symposium, and it is hoped that they will contribute to the emerging field of humanitarian logistics and supply chain management.

The paper by Jahre, Jensen, and Listou highlights the need for the development of an appropriate theoretical framework for the analysis of humanitarian logistics and supply chain management. Having given consideration to the particular characteristics of humanitarian logistics operations, the authors look for potentially relevant theories and concepts drawn from the literature that has been developed in relation to the commercial sector. They identify three constructs that provide a useful starting point for the analysis of humanitarian logistics activity: vertical and horizontal coordination; permanent and temporary networks; centralised vs decentralised logistics structures, and show how these can be combined into a logical framework with which to approach humanitarian scenarios. They also consider the relevance of postponement/speculation strategies in humanitarian activity where supply chains lie dormant during the preparedness phase but need to be mobilised and effective at short notice. The paper 
goes on to outline proposed empirical studies to evaluate the relevance of the theoretical framework in three contrasting humanitarian organisations.

Careful selection of appropriate theories from commercial logistics and supply chain management followed by evaluation and, where necessary, adaptation to the particular circumstance of humanitarian aid, is an important contribution that the academic community can make to the development and enhancement of humanitarian logistics activity.

The paper presented by Carroll and Neu also addresses the need for the development of a theoretical framework. Having reviewed literature in relation to commercial, military and humanitarian logistics, they identify three key features: volatility, unpredictability and asymmetry that are present in all three sectors albeit due to different causes and with different manifestations. They point out the need for further research in a variety of aspects of humanitarian logistics including the development of proactive performance measures for supply chain effectiveness, the development of ICT systems, analysis of the overall impact of logistics capability on humanitarian response programmes, and the development of collaborative relationships - and it is relevant to note that a number of these themes are taken up in other papers within this special edition. In synthesising some of the approaches and challenges in the development of integrated humanitarian logistics and supply chain management, the authors conclude by highlighting the need for training and education of logistics personnel (at both the operational and strategic levels) as a fundamental requirement for the development of more efficient supply chain operations.

The need for appropriate measures for humanitarian supply chain activity is addressed in the paper by Schultz and Heigh, which describes a case study of the development and implementation of a set of metrics to monitor the operations and development of logistics activity in the International Federation of Red Cross and Red Crescent Societies (IFRC). This contribution, which has won the Award for the best paper presented at the $2007 \mathrm{CCHLI}$ International Symposium, sets the context for the case study by considering the need for, and the characteristics of, metrics in any logistics system and then goes on to describe a number of approaches commonly used in the commercial sector such as the Balanced Score Card and the "SCOR" models. The case study gives a clear overview of the important phases in the development of the performance measurement tool by the IFRC, and outlines the key features of the tool. The chosen KPIs measure four critical dimensions of logistics management namely: customer service, financial control, process adherence and innovation/learning, and useful practical details are given of the key metrics used to monitor each of these four dimensions. In conclusion, the authors offer an evaluation of some of the practical challenges and critical success factors in implementing a performance measurement tool in a large international organisation which has logistics centres spread across the world. This paper represents one of the first published accounts giving details of the practicalities of devising and implementing a logistics measurement system for humanitarian aid operations. As the authors point out, they hope that it will provide a useful guide to other aid organisations that aspire to develop more effective systems to monitor and improve logistics activity.

The paper presented by McLachlin, Larson, and Khan explores the extent to which the concepts and tools used in commercial sector logistics are applicable in the humanitarian relief context. It illustrates how the environment in which humanitarian logistics takes place has significant differences to most commercial operations, and a 
two-dimensional framework is presented distinguishing motivations (for-profit vs not-forprofit) and environments (uninterrupted vs interrupted). The paper includes a useful overview of the current status and challenges of logistics and supply chain management in the humanitarian sector. The theoretical discussion is followed by a case study of an independent charity based on qualitative research exploring the issues facing the charity in terms of logistics and supply chain management. Two key factors emerge: the importance of collaboration and performance measurement - both of which further emphasise themes mentioned in other papers in this edition. Although partnership strategies and KPI's are also very pertinent issues in the commercial environment, the case gives a clear view of the nature and particular nuances of these issues in a not-for-profit charity. In so doing it reveals some interesting perspectives on the aims and objectives of the particular NGO studied. The insights offered from this case also offers pointers to the sensitivities required in approaching supply chain improvement in other humanitarian agencies.

The paper by Tysseland deals with another very practical issue in humanitarian logistics - that of vehicle spare parts management. The study is centred on the comparison of the approaches adopted by the Norwegian military and the Norwegian Red Cross in planning for vehicle maintenance for relief efforts in Darfur. Ensuring spare parts availability is a critical issue in many disaster situations as there is often a lack of local vehicle repair capability, yet the maintenance of the vehicle fleet is vital in ensuring the continuity of the supply pipeline. The paper considers some of the detailed practical issues of spare parts planning and management when operating in distant locations, and highlights some of the key the differences in the approaches taken by the two case organisations. For example the military's use of a range of sophisticated vehicles and equipment significantly complicates the spares management task, and is in stark contrast to the specification of one relatively simple truck type used by the Red Cross. As with the paper by McLachlin et. al., this study also considers the organisational context in which logistics activity takes place, and emphasises the important bearing that this has on the operational practicalities. Whereas the former paper looks at the influence of organisational culture on the aid agency's objectives and relationships, Tysseland's paper highlights the impact of organisational structures and the presence/absence of logistics expertise on the effectiveness of spare parts inventory planning in support of aid operations.

The final paper included in this special edition is written by two logisticians Whiting and Ayala-Öström, both of whom have had considerable field experience in humanitarian aid operations. The paper gives a considered overview of the position and status of logistics and supply chain management in the humanitarian sector, and underlines the need for advocacy of supply chain management at the highest levels within aid organisations. Following a review of worldwide expenditure on humanitarian aid, the authors point out that logistics costs represent a very high proportion of aid budgets up to 40 per cent, compared to 15 per cent as more common in commercial sectors. In spite of this, or possibly explaining this, it is argued that logistics and supply chain management is still poorly understood within the humanitarian sector. In particular, the authors suggest that there is a lack of appreciation at senior level in both aid agencies and donor agencies of the scope and extent of logistics and supply chain management, its strategic role and the opportunities for operational improvement. They also point out that deficiencies in humanitarian logistics activity have become very apparent in a number of recent disasters and highlight the need for improvements in human resource management, inter-agency collaboration, needs assessment and the use of ICT. Most importantly, however, this paper stresses the need for advocacy of role of logistics and 
supply chain management to senior level policy makers in both aid agencies and donor organisations. It is argued that, unless logistics is elevated to the strategic level, it is unlikely that the resources and commitment required for significant operational improvement will be made available.

In summarising the issues raised in these papers, the editors of this Special Edition would suggest that raising the status of logistics and supply chain management requires a significant change in corporate mind sets, and note that this almost always proves to be a difficult and slow process. In the commercial sector, such a change in perspective has been driven by market forces including, for example, increasing demands from customers for better service, continual pressure to reduce costs, competition from low cost economies and the continual search for competitive advantage. In the humanitarian sector many of theses forces are absent or less apparent. The "voice of the real customer" (i.e. the actual beneficiaries) is weak or unheard; there is no competitive pressure between aid agencies to improve logistics performance; there is a lack of clear measures with which to evaluate performance even against previous aid missions and there is, perhaps, a feeling in some agencies that "we are doing our best, in difficult conditions", even though that might not be the best possible. In these circumstances elevating the status of logistics and supply chain management in the humanitarian sector is going to be particularly challenging - but arguably it is in this role that the academic community can make a useful contribution by objective analysis of current humanitarian operations, by introduction and adaptation of theories and best practices from the commercial world, and by provision of training and education for humanitarian logistics and supply chain professionals.

It is also clear that there is a need for robust empirical studies which will aid the development of arguments for a change in approach and emphasis. To take but one example, there is a marked difference between the estimates of the percentage of expenditure devoted to logistics as derived by Van Wassenhove (2006) on the one hand, and Whiting and Ayala-Öström on the other. Development of sound data is essential to underpin the arguments both within a given NGO/Agency and with donor bodies - no one doubts the need to improve the logistic performance in support of disasters, but arguments to achieve this should be supported by clear, robust analysis of accurate and verifiable data.

In conclusion, the editors of this special edition would like to thank all those who have contributed and especially to the reviewers who have carried out this task with considerable enthusiasm and insight. We would also wish to extend our particular thanks to Professor Joseph Sarkis who has been an invaluable mentor throughout the process of bringing this special issue to fruition. We hope that you find the articles interesting and valuable, and that they will inspire even more research in the emerging field of humanitarian logistics and supply chain management with the concomitant benefits to those affected by future disasters.

\section{References}

Balcik, B. and Beamon, B.M. (2008), "Facility location in humanitarian relief", International Journal of Logistics: Research and Applications, Vol. 11 No. 2, pp. 101-22. CRED (Centre for the Research on the Epidemiology of Disasters) (2008), 2007 Disaster Statistics, available at: www.emdat.be Fritz Institute (2005), From Logistics to Supply Chain Management: The Path Forward in the Humanitarian Sector, available at: www.fritzinstitute.org 
HUMLOG (2009), Available at: www.humloggroup.org

IFRC (2005), International Federation of Red Cross Worlds Disaster Report, available at: www.ifrc.org/publicat

OCHA (2006), Update on Humanitarian Reform; UN Office for the Coordination of Humanitarian Affairs, New York, NY, March.

UN (United Nations) (2006), "Strengthening the coordination of emergency

humanitarian assistance of the United Nations", Report by the Secretary-General to the General Assembly 61st Session, Item 67(a) of the preliminary list, available at:

www.un.org (accessed 2 June).

Van Wassenhove, L.N. (2006), "Humanitarian aid logistics: supply chain management in high gear", Journal of the Operational Research Society, Vol. 13 No. 1, p. 26.

Wilton Park (2005), Improving National and Regional Disaster Capacity. Report of the Wilton Park Conference WPS05/20, available at: www.wiltonpark.org.uk

\section{About the authors}

\section{Peter H. Tatham}

Joined the Royal Navy in 1970 and served in a variety of appointments during his career of some 35 years. Highlights include Logistics Officer of the Aircraft Carrier HMS INVINCIBLE in 1994/1995 during Operations in Bosnia against the Former Republic of Yugoslavia and Chief Staff Officer responsible for all high level Personnel and Logistics issues emanating from the 10,000 sailors and 30 surface ships in the Royal Navy (1999-2000). His final three years in the Service were spent in the Defence Logistics Organisation where he was responsible for key elements of the internal programme of Change Management (2000-2004). During this period, he also gained an MSc in Defence Logistic Management. Following his retirement from the RN, he joined the staff of Cranfield University where he lectures on Defence and Humanitarian Logistics, and in Human Systems. He is also carrying out his Doctoral research into the issues surrounding the role of shared values within military supply networks. Peter H. Tatham is the corresponding author and can be contacted at: p.h.tatham@cranfield.ac.uk

\section{Karen M. Spens}

Professor of Supply Chain Management and Corporate Geography at the Swedish School of Economics and Business Administration (Hanken) in Helsinki, Finland. She earned her PhD in from Hanken in 2001, and has since published articles in logistics journals such as International Journal of Physical Distribution and Logistics Management and the International Journal of Logistics Management. She has also edited several special issues for different journals. Her research interests include humanitarian logistics, health care related research and methodological issues in logistics and supply chain management.

\section{David Taylor}

Senior Research Fellow at Cardiff Business School and Co-Director of the Food Process Innovation Unit. He joined Cardiff in 1997 and has carried out various research projects to develop and apply lean concepts to supply chain management. He has published two books and numerous articles and has worked in various sectors including metals, engineering, shipbuilding, footwear and agri-foods. He is currently exploring how lean principles and value chain analysis can be applied to humanitarian aid supply chains. 
The Fritz Institute has adapted the definition of commercial supply chain management coined by the US Council of Supply Chain Management Professionals to define humanitarian logistics "as the process of planning, implementing and controlling the efficient, cost-effective flow and storage of goods and materials, as well as related information, from point of origin to the point of consumption for the purpose of alleviating the suffering of vulnerable people" (www.fritzinstitute.org). The authors of this article concur with this definition in this edition. 